\title{
Validity of the Physical Activity Behavior Questionnaire (QCAF) Among Healthy and Unhealthy Individuals
}

\section{${ }^{1 *}$ São-João, Thaís Moreira, ${ }^{2}$ Rodrigues, Roberta Cunha Matheus, ${ }^{3}$ Amireault, Steve, ${ }^{4}$ Mendez, Roberto Della Rosa, ${ }^{5}$ Gallani, Maria-Cecília Bueno Jayme}

\author{
Authors details: \\ ${ }^{1 *}$ São-João, Thaís Moreira. $\mathrm{PhD}$, \\ Assistant Professor - School of \\ Nursing, University of Campinas - \\ São Paulo, Brazil. \\ *Corresponding author: \\ tsaojoao@unicamp.br \\ ${ }^{2}$ Rodrigues, Roberta Cunha \\ Matheus. PhD, Full Professor - \\ School of Nursing, University of \\ Campinas - São Paulo, Brazil. \\ ${ }^{3}$ Amireault, Steve. PhD, Assistant \\ Professor - College of Health and \\ Human Sciences, Purdue \\ University - Indiana, US \\ ${ }^{4}$ Mendez, Roberto Della Rosa. \\ $\mathrm{PhD}$, Assistant Professor - \\ Department of Nursing and \\ Biotechnology, Federal University \\ of Mato Grosso do Sul - Mato \\ Grosso do Sul, Brazil. \\ ${ }^{5}$ Gallani, Maria-Cecília Bueno \\ Jayme. PhD, Full Professor - \\ Faculté des sciences infirmières, \\ Université Laval - Québec, \\ Canada.
}

\begin{abstract}
Aim: The aim of this study was to test the convergent and divergent validity of the Physical Activity Behavior Questionnaire (QCAF, acronym in Portuguese for Questionário do Comportamento de Atividade Física), an instrument developed based on the Theory of Planned Behavior.
\end{abstract}

Methods: An exploratory study was conducted in an outpatient clinic among 236 individuals referred for cardiopulmonary exercise testing with oxygen uptake. Coronary heart disease, hypertensive and healthy individuals were enrolled. PA was measured by the QCAF and the Baecke Habitual PA Questionnaire (Baecke-HPA). Cardiorespiratory fitness was estimated by the Veterans Specific Activity Questionnaire (VSAQ), the peak $\left(\mathrm{VO}_{2 \text { peak }}\right)$ and the maximum oxygen uptake $\left(\mathrm{VO}_{2 \max }\right)$. Results: The convergent validity was verified by the confirmed relation between the QCAF and the measures of physical activity - Baecke-HPA $\left(r_{a d j}=0.32 ; p<0.0001\right)$ and cardiorespiratory fitness $-\mathrm{VO}_{2 \text { peak }}\left(r_{a d j}=0.15\right.$; $\mathrm{p}=0.02), \mathrm{VO}_{2 \max }\left(\mathrm{r}_{\mathrm{adj}}=0.13 ; \mathrm{p}=0.05\right)$ and VSAQ $\left(\mathrm{r}_{\mathrm{adj}}=0.13 ; \mathrm{p}=0.05\right)$. The divergent validity was confirmed by the absence of significant correlations between the QCAF and the Occupational Physical Activity domain of the Baecke-HPA ( $\mathrm{r}=0.04 ; \mathrm{p}=0.49)$, as expected.

Conclusion: The QCAF presented acceptable levels of convergent and divergent validity, demonstrating to be a useful tool in order to measure walking among a diverse adult population.

Keywords: Validation Studies; Questionnaires; Motor Activity; Coronary Disease; Hypertension; Psychometry. 


\section{Introduction}

Health workers constantly face the task of recommending physical activity (PA) to patients, being them healthy or not, in order to manage cardiovascular risk factors or a settled health condition. Walking is signally appropriated to PA prescription for both active and inactive individuals hence it is accessible to people of any age and social clusters and its accomplishing presents slight risk of injury (Murtagh, Murphy, \& Boone-Heinonen, 2010). Of all types of PA, walking stands out as the most popular form of leisuretime PA (LTPA) (Ham, Kruger \& TudorLocke, 2009) being also a functional part of activities of daily living and providing numerous health benefits (Lee, Rexrode, Cook, Manson \& Buring, 2001). In contrast, poor walking performance is predictive of heart disease and osteoporosis and increases the risk of death in the elderly (Lee, Rexrode, Cook, Manson \& Buring, 2001; Nogueira, Baitelli, Alvarenga \& Thuler, 2012).
Therefore, properly measuring this behaviour presents massive importance. In this sense, the Psychosocial Determinants of Physical Activity among Coronary Heart Disease Patients Questionnaire (Mendez, Rodrigues, Cornélio, Gallani \& Godin, 2010) was developed based on the constructs of the Theory of Planned Behavior (TPB) (Ajzen, 1988), in which the main frame states that the intention is the key determinant of the behaviour of an individual; and originally aimed at measuring PA among coronary heart disease (CHD) outpatients. The aim of this particular instrument is to assess the pattern of walking for at least 30 minutes, 3 times per week. The complete questionnaire is composed of 30 items, in order to elicitate determinants of behaviour, as intention and perceived behavioral control, and one item despite the behaviour itself has been included. This one-item excerpt has been denominated The Physical Activity Behavior Questionnaire (QCAF, derived 
from the original name in Portuguese Questionário do Comportamento de Atividade Física).

The above-mentioned questionnaire was developed and tested for its reliability regarding internal consistency and content validity in previous study aimed at identifying the determinants of the behavior of walking among coronary heart disease (CHD) outpatients (Mendez, Rodrigues, Cornélio, Gallani \& Godin, 2010). Nevertheless, "the TPB represents one of the most empirically supported theories of social psychology for the prediction of health-related behaviors" (Godin , Bélanger-Gravel, Amireault, Vohl \& Pérusse, 2011). In this sense, the use of QCAF could support designing studies based on psychosocial theories, once it has demonstrated evidences of content validity and reliability. However, valid measures are necessary to allow the general utilization of a measure and, among others, determine whether the study population meets PA recommendations. More recently, the measurement of the frequency of walking extracted of this instrument has been used to measure LTPA as well as to evaluate the effect of interventions aimed to promote active behavior in cardiac patients, with evidences of reliability (Rodrigues, Gallani, Cornélio, Alexandre \& São-João, 2013).

Therefore, valid and reliable measures of physical activity (PA) are essential to certificate the frequency, duration and distribution of PA in diverse populations; as to assess the predominance of persons gathering health recommendations; to study the result of different intensities of PA on health outcomes; to allow cross-cultural comparisons and to examine the effects of interventions (Helmerhorst, Brage, Warren, Besson \& Ekelund, 2012). PA questionnaires, therefore, are frequently the most viable method to assess PA because of their low cost and convenience. Nevertheless, these instruments have limitations as measurement error and bias that may be 
deliberate, as social desirability; or related

to cognitive limitations as recall or

understanding (Helmerhorst, Brage,

Warren, Besson \& Ekelund, 2012).

PA constitutes essential part in the prevention of cardiovascular diseases, as well as of cardiac rehabilitation programs. The nursing team in Brazil represents the most significant percentage of health professionals at the Public Health System with an impressive capacity to reach a massive proportion of the population. Therefore, nurses in this context can have a pivotal role in the development, implementation and evaluation of interventions aimed at changing healthrelated behaviors, as increasing the level of PA in special populations as patients with cardiovascular diseases. In this context, the use of theory-based PA questionnaires is crucial to correctly measure PA behavior and provide the key elements for the measurement of the effect of the intervention (Rodrigues, Gallani, Cornélio, Alexandre \& São-João, 2013).
Even considering the more recurrent use of objective methods to assess PA, questionnaires remain as a practical technique in surveillance systems, for risk stratification and for examining etiology of disease in observational studies (Helmerhorst, Brage, Warren, Besson \& Ekelund, 2012).

Therefore, considering the relevant lack of specific instruments aimed at measuring walking behavior for a heterogeneous sample in the Brazilian context, the aim of this study is to demonstrate the evidences of validity of the QCAF in a diverse population, composed by healthy and non-healthy participants. Its specific aims are to test the convergent and divergent validity with direct and self-reported measures of cardiorespiratory fitness and physical activity. It is expected that the refinement of measurement properties of a selfreported walking questionnaire (QCAF) will contribute to the availability of tools with evidences of validity and reliability, 
which can be used to measure the behavior itself and moreover, the effect of interventions aimed at promoting physical activity such as programs for secondary prevention and / or cardiac rehabilitation.

\section{Methods}

\subsection{Type of study and settings}

This exploratory study was carried out in the Southeastern region of Brazil. Data were gathered during a 5-month period. A random sample of participants was recruited from an outpatient public clinic.

\subsection{Sample size}

A minimum sample size of 100 patients was established, according to the European Research Group on Health Outcomes, which indicates this size to be ideal for this type of study when there is a clear description of the procedures (Meadows, Bentzen, \& Touw-Otten, 1996). Considering this sample size, participants who attended inclusion criteria were sequentially included along the time agreed for data collection procedures.

\subsection{Participants}

Participants were recruited at the day of their regular appointment for the cardiopulmonary exercise test, conducted by a cardiologist and accompanied by a nurse or a physical therapist to carry out the gas analysis. They were then invited to participate in the research and their agreement was formalized by signing a consent term. The final sample comprised 236 individuals distributed among three groups: healthy volunteers $(\mathrm{n}=100)$, hypertensive outpatients $(\mathrm{n}=100)$ and coronary heart disease (CHD) outpatients $(n=36)$.

For systematic verification of the inclusion of healthy subjects in the study, there was a checklist of inclusion criteria of healthy individuals. Information about patient's health problems such as hypertension, heart disease (myocardial infarction, angina, Chagas disease, heart failure), diabetes, orthopedic disease, 
vascular disease, high cholesterol, cancer, walking ability and use continuous medication were gathered. The inclusion of the individual after the conference of the items in the checklist evidenced that they did not have an unhealthy condition at that time, that would impair them of walking. Hypertensive and CHD patients declared if they had one of these diagnoses, or both; or they were classified as so if the physician conducting the cardiopulmonary exercise test considered them as so.

\subsection{Questionnaires}

All instruments were administered to the sample through an interview, as described anywhere (Pereira, Folsom, McGovern, Carpenter, Arnett, Liao, Szklo \& Hutchinson, 1999), given the low educational level of the participants. It is worthy to highlight that QCAF was designed to be administered by interview, but both Baecke-HPA and VSAQ were primarily created as auto-administered questionnaires - despite they have been administered differently over the last few years (Domingues, Gallani, Gobatto, Miura, Rodrigues \& Myers, 2011; Rodrigues, Gallani, Cornélio, Alexandre \& São-João, 2013).

\subsubsection{Clinical and sociodemographic data}

Sociodemographic data was obtained through interview regarding age, gender, marital status, race, education level, employment status and family income. Clinical data was gathered through analysis of medical records and interview. Clinical associated conditions were assessed - hypertension, diabetes, dyslipidemia, current or past smoking and drinking; and perceived cardiovascular symptoms in the last month were evaluated - angina, fatigue, palpitation, cephalea, edema, fainting and dyspnea. The instruments applied to collect sociodemographic and clinical data were tested regarding the content validity in earlier studies (Cornélio, Gallani, Godin, Rodrigues, Mendez \& Nadruz Junior, 2009; Mendez, Rodrigues, Cornélio, 
Gallani \& Godin, 2010). Direct measures were made to obtain anthropometric data (weight $(\mathrm{kg})$ and height $(\mathrm{cm})$ ). Participants were weighed and measured at the time preceding the interview, using a single anthropometric validated scale (Filizola ${ }^{\circledR}$ Personal PL200), allocated in the search field. During the measures all the subjects were asked to remove their shoes and leave the arms extended on the side of the body, keeping his head up like look facing forward. Body Mass Index (BMI) was calculated by the formula $=$ (weight $/$ height $^{2}$ ). Blood Pressure measurements were taken according to the recommendations of the VI Brazilian Guidelines on Hypertension (2010).

\subsubsection{Measures of Physical Activity}

- The Physical Activity Behavior Questionnaire - QCAF

This measure consists of an excerpt from the Psychosocial Determinants of Physical Activity among Coronary Heart Disease Patients Questionnaire (Mendez, Rodrigues, Cornélio, Gallani \& Godin, 2010), regarding Behavior. The aim of this instrument is to assess the pattern of walking for at least 30 minutes, 3 times per week. The complete questionnaire consists of 30 items distributed to evaluate the following constructs: Behavior (1 item), Intention (6 items), Attitude (5 items), Subjective Norm (4 items), Perceived Behavior Control (5 items), Self-efficacy (2 items), Habit (5 items) and Perceived Risk (2 items); and has been validated regarding content validity and tested despite its reliability, with Cronbach's alpha above 0.70 , indicating satisfactory internal consistency among coronary heart disease outpatients in previous studies (Mendez, Rodrigues, Cornélio, Gallani \& Godin, 2010; Spana, Rodrigues, Gallani \& Mendez, 2010).

In the original study, the item for measuring Behavior was designed as the following: "Over the last six months before your infarction, how many times have you walked for at least 30 minutes: (1) less than once a week, (2) once a week, 
(3) twice a week, (4) three or more times a week". In our study, the item has been adapted to the general population and modified regarding the time period. Therefore, in this question, respondents were asked "In the last month, how many times have you walked for at least 30 minutes?". The answer was measured the same manner as the original questionnaire.

\section{- Habitual Physical Activity - The Baecke}

\section{Questionnaire}

The Brazilian version (Florindo, Latorre, Jaime, Tanaka\& Zerbini, 2004) of the Baecke Questionnaire of Habitual Physical Activity (Baecke-HPA) was applied. The Baecke-HPA is easy to understand and apply, and ensures qualitative and quantitative indices through 16 questions encompassing three dimensions of PA in the past 12 months: 1) occupational PA (OPA - 8 questions); 2) physical exercises in leisure (PEL - 4 questions); and 3) leisure and locomotion physical activities (LLA - 4 questions). The items are scored on a five-point Likert scale, ranging from never up to always, generating each dimension, scores from 1 up to 5, with higher scores indicating higher levels of PA. The total score (HPAscore) is a summation of the three dimensional scores and the range varies from 3 (inactive) up to 15 (very active). This questionnaire has been used among healthy (Florindo \& Latorre, 2003) and non-healthy (Ono, Hirata, Yamada, Nishiyama, Kurosaka \& Tamura , 2007) population and it is considered a valid and reliable tool for measuring PA.

\subsubsection{Measure of Cardiorespiratory}

Fitness

- The Veterans Specific Activity Questionnaire (VSAQ)

The Brazilian version of the VSAQ (Domingues, Gallani, Gobatto, Miura, Rodrigues \& Myers, 2011) was applied prior to exercise testing. The VSAQ allows the determination of different intensities of daily activities that are limited by cardiovascular disease symptoms. The VSAQ consists of a list of activities 
presented in progressive order according to Metabolic Equivalent Tasks (MET). The scale ranges from 1 (one) up to 13 (thirteen) METs. The MET values associated with each activity were derived from the Brazilian version of the Compendium of Physical Activities (Farinatti, 2003). The VSAQ score was age-adjusted by using a nomogram according to the equation: METs $=4.7+$ 0.97 (VSAQ) - $0.06 \quad$ (age), as recommended by the authors of the original questionnaire (Myers, Do, Herbert, Ribisl \& Froelicher, 1994).

- Cardiopulmonary exercise testing with oxygen uptake

Exercise testing with oxygen uptake analysis was performed on a treadmill using ramp protocol, as recommended in order to optimize exercise testing when gas analyses are conducted (Myers, Buchanan, Smith, Neutel, Bowes, Walsh \& Froelicher, 1992). The exercise was terminated for generalized fatigue, symptom or sign limits, or electrocardiographic changes in all participants, according to the Brazilian Society of Cardiology criterion (Meneghelo, Araújo, Stein, Mastrocolla, Albuquerque \& Serra, 2010). Oxygen uptake was determined and averaged every 10 seconds using the MedGraphics VO2000 portable metabolic measurement system and the software Aerograph (Medical Graphics Corp., St.Paul, MN). Gas exchange was obtained with the individual wearing a nose clip and a facial mask, breathing room air through a 1-way directional valve system. Peak oxygen uptake $\left(\mathrm{VO}_{2 \text { peak }}\right)$ was defined as the maximum attained oxygen consumption at the end of exercise testing. Calibration of the system was performed daily. In the present study, the maximum oxygen uptake $\left(\mathrm{VO}_{2 \max }\right)$ was estimated based on the equation proposed by the American College of Sports Medicine and recommended by the American Heart Association (Balady, Arena, Sietsema, Myers, Coke, Fletcher, Forman, Franklin, 
Guazzi, Gulati, Keteyian, Lavie, Macko, Mancini \& Milani, 2010), considering $\mathrm{VO}_{2 \max }$ as the highest rate at which oxygen can be taken up and utilized by the body during severe exercise (Bassett \& Howley., 2000).

In the setting where the study was conducted, participants were commonly advised by their doctor to stop taking betablockers in the past three or five days before the test. This is a frequent recommendation for this type of test, since the use of beta-blockers may increase workload at estimated lactate threshold, oxygen pulse and heart rate both at estimated lactate threshold and peak (West, Parry, Asher, Key, Walker, Loughney, Pintus, Duffy, Jack \& Torella, 2015). If for any reasons (like forgetting or neglecting this advice) participants were in use of beta-blockers in the day of the schedule test, despite the medical recommendations, the test was rescheduled.

\subsection{Statistics}

In order to evaluate validity, adjusted correlations controlling for sex, age, education, Body Mass Index and disease groups (CHD or Hypertension) were determined between the QCAF and the Baecke-HPA; and between the QCAF and the direct $\left(\mathrm{VO}_{2 \text { peak }}\right)$ and indirect (VSAQ and $\left.\mathrm{VO}_{2 \max }\right)$ measures of cardiorespiratory fitness, considering correlation coefficients magnitude of 0.10 as small, 0.30 as moderate and 0.50 as large (Cohen, 1992). Analyses to verify the presence of univariate or multivariate outliers were conducted and if present, they were excluded. The Statistical Analysis System for Windows program, version 9.2 (SAS Statistical Analysis System Institute Inc., Cary, NC, USA, 2008) was used for all statistical analyses.

\subsection{Ethical aspects}

Participants were invited to engage in the research and their agreement was formalized by signing a consent term. Ethical approval was granted from the local ethics committee (Document $n$. 
1.062/2009). All participants provided informed voluntary consent.

\section{Results}

Sociodemographic and clinical characterization

The sample was composed mostly by females $(58.5 \%)$, with mean age of $52.8(11.1)$ years, with few years of formal education (5.7) and low family monthly income (US\$ 911.7). The majority of the sample was white $(82.2 \%)$, living with companion (72.8\%) and professionally active $(51.7 \%)$. The number of symptoms ranged from 0 up to 7 , with similar means for the total sample, hypertensive individuals and CHD group $(2.2 \times 2.1 \times$ 2.6). Symptoms and associated clinical conditions were not evaluated among healthy volunteers, since they were not supposed to present any because of their healthy condition (Table I).

Among the evaluated symptoms, angina was the most frequently reported over the last month in both hypertensive and CHD groups. The number of associated clinical conditions ranged from 0 up to 5. Past or current smoking was more prevalent among CHD patients and alcohol use (past or current) was low and similar in the three groups. The number of medications in use oscillated from 0 up to 12, with the highest mean for the CHD group (4.4). The analysis of the Body Mass Index (BMI) revealed predominance of obese and over weighted participants, with higher mean for the hypertensive patients and similar means for healthy volunteers and CHD patients (Table I). 
Table I. Sociodemographic and clinical characterization of the total sample $(\mathrm{n}=236)$ and groups - hypertensive patients $(\mathrm{n}=100)$, patients with coronary heart disease (CHD, $n=36)$ and healthy volunteers $(n=100)$. Campinas, 2014.

Total sample $(n=236) \quad$ Healthy $(n=100) \quad$ Hypertensive $(n=100) \quad$ CHD $(n=36)$

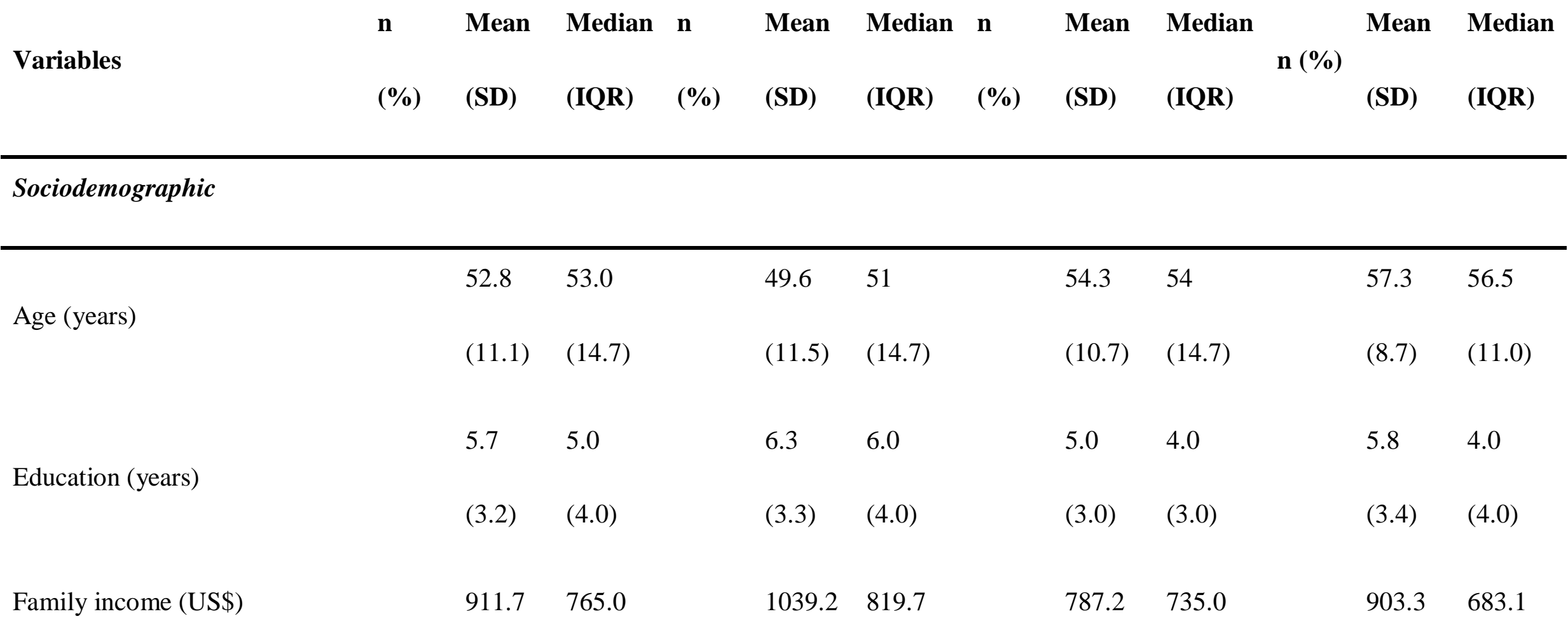


$(620.7) \quad(588.2)$

138

(58.5)

194

(82.2)

Color - White

Marital status - With 172

companion

Professional status
122

(51.7)

114

Non-active/ Housewife

(72.8)

Active

(48.3)
(730.1) (726.5)

(410.9) (470.6)

(714.7) (488.2)

52

73

13

(73.0)

(36.1)

30

(83.3)

30

(70.0)

(72.0)

14

(38.9)

22

(61.1) 


\begin{tabular}{|c|c|c|c|c|c|c|c|c|}
\hline Clinical & & & & & & & & \\
\hline \multirow{3}{*}{ Associated clinical conditions } & 2.2 & 2.0 & & & 2.1 & 2.0 & 2.6 & 3.0 \\
\hline & & & -- & -- & & & & \\
\hline & $(1.0)$ & $(2.0)$ & & & $(1.0)$ & $(2.0)$ & (1.1) & $(1.0)$ \\
\hline \multirow{2}{*}{ BMI } & 29.6 & 29.1 & 28.3 & 28.2 & 31.2 & 30.2 & 28.7 & 27.7 \\
\hline & $(5.6)$ & $(6.8)$ & $(5.0)$ & $(6.9)$ & $(6.0)$ & $(8.3)$ & $(4.9)$ & $(7.5)$ \\
\hline
\end{tabular}

*SD: Standard Deviation; ${ }^{\dagger} \mathrm{IQR}$ : Interquartile Range; ${ }^{*} \mathrm{US} \$$ : United States Dollar. 
3.1 Descriptive analysis of Physical Concerning the Baecke-HPA, the mean Activity and Cardiorespiratory Fitness total score observed was 7.2 (Table II).

Measures

The measures of cardiorespiratory

The self-report measures of PA fitness also exhibited low levels. The reveal a low perceived level of VSAQ presented a mean of 6.3(2.8) accomplished PA. Regarding the QCAF assessment, the majority of participants reported low scores of walking behavior, with a mean score of 1.7 , which is lower than the half of the possible maximum score. The main fraction of the sample $(82,2 \%, n=194)$ reported frequency of walking smaller than 3 times per week. METs, fnding that was supported by objective measures - the $\mathrm{VO}_{2 \text { peak }}$ mean was 19.7(5.7) $\mathrm{ml} \cdot \mathrm{kg}^{-1} \cdot \mathrm{min}^{-1}$ and the $\mathrm{VO}_{2 \max }$ mean was 29.1(11.3) $\mathrm{ml} \cdot \mathrm{kg}^{-1} \cdot \mathrm{min}^{-1}$. Among this sample, 5 out of the 236 patients did not present gas analysis due to technical difficulties during data collection (Table II).

Table II. Descriptive analyses of Physical Activity and Cardiorespiratory Fitness of the total sample (n=231). Campinas, SP, Brazil, 2014.

$Q C A F$

(1-4; higher score $=$ higher $\left.P A^{\S}\right)$

Score 
2 times/week (3)

3 or more times/week (4)

42(17.8)

\section{${ }_{\text {Baecke-HPA }}$}

Occupational Physical Activity

$1.1-$

(1-5; higher score $=$ higher

occupational PA)

Physical Exercise in Leisure

$1.0-$

(1-5; higher score= higher physical

2.1(0.6) 2.0(0.7)

exercise in leisure)

Activities of Leisure and Locomotion

(1-5; higher score $=$ higher leisure

$1.0-$

4.5

2.5(0.6) 2.5(1.0)

and locomotion PA)

Total Score
(3-15; higher score=higher total
$3.9-12$
$7.2(1.5) \quad 7.2(2.0)$

Habitual PA)

\section{Cardiorespiratory Fitness Measures}

Mean

Median

Range

(SD)

(IQR)

\section{Direct}
${ }^{\mathbb{I}} \mathrm{VO}_{2 \text { peak }}\left(\mathrm{ml} \cdot \mathrm{kg}^{-1} \cdot \mathrm{min}^{-1}\right)$
$8.2-42.4$
19.7(5.7)
19.2(6.9) 


\section{Indirect}

\begin{tabular}{|c|c|c|c|}
\hline *** VSAQ & $1.5-14.5$ & $6.3(2.8)$ & $5.8(4.3)$ \\
\hline${ }^{\dagger} \mathrm{VO}_{2 \max }\left(\mathrm{ml} \cdot \mathrm{kg}^{-1} \cdot \mathrm{min}^{-1}\right)$ & $3.5-59.4$ & 29.1(11.3) & $27.2(17.5)$ \\
\hline
\end{tabular}

"SD: Standard Deviation; ${ }^{\dagger} \mathrm{IQR}$ : Interquartile Range; ${ }^{\dagger} \mathrm{QCAF}$ : Self-reported Behavior measure;

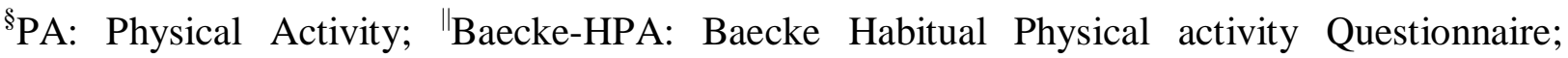
${ }^{\mathbb{I}} \mathrm{VO}_{2 \text { peak: }}$ Peak oxygen consumption; ${ }^{* *}$ VSAQ: Veterans Specific Activity Questionnaire; ${ }^{\dagger} \mathrm{VO}_{2 \max }$ : Maxymal oxygen consumption.

\subsection{Convergent and divergent} validity

Regarding the analyses between the QCAF and the Baecke-HPA, significant positive moderate-large correlations were observed with the Physical Exercise in Leisure (PEL) sub score; significant positive small-moderate correlations were observed with the Locomotion and Leisure Activities (LLA) sub score and significant positive moderate correlations were observed with the Total score. No significant correlations were observed between the QCAF and the Occupational Physical Activity, as expected in order to confirm its divergent validity (Table III). 
Table III. Correlation between the QCAF, the Baecke-HPA total score and sub-scores, $\mathrm{VO}_{2 \text { peak }}$, VSAQ and $\mathrm{VO}_{2 \max }$ for the total sample $(\mathrm{n}=231)$. Campinas, SP, Brazil, 2014.

\section{Baecke-HPA ${ }^{*}$}

\section{QCAF}

$$
\mathrm{r}^{\dagger}(\mathrm{p} \text {-value })
$$

Occupational Physical Activity

$0.04(0.49)$

Physical Exercise in Leisure

$0.46(<0.0001)$

Activities of Leisure and Locomotion

$0.16(<0.05)$

Total Habitual PA Score

$0.32(<0.0001)$

\section{Cardiorespiratory fitness measures}

$\begin{array}{lc}\mathrm{VO}_{2 \text { peak }}{ }^{\ddagger} & \mathbf{0 . 1 5}(\leq 0.05) \\ \mathrm{VO}_{2 \text { max }}{ }^{\S} & \mathbf{0 . 1 3}(\leq 0.05) \\ \mathrm{VSAQ}^{\|} & \mathbf{0 . 1 3}(\leq 0.05)\end{array}$

*Baecke-HPA: Baecke Habitual Physical activity Questionnaire; ${ }^{\dagger}$ r: adjusted correlation controlling for sex, age, Body Mass Index (BMI), education and groups (CHD and hypertension); ${ }^{*} \mathrm{VO}_{2 \text { peak }}$ : Peak oxygen consumption; ${ }^{\S} \mathrm{VO}_{2 \max }$ : Maxymal oxygen consumption; "VSAQ: Veterans Specific Activity Questionnaire. 
Concerning the analyses between the QCAF and the cardiorespiratory fitness measures, it was observed that the questionnaire presented significant correlations with both direct and indirect measures. Significant positive small correlations were observed between the QCAF and the $\mathrm{VO}_{2 \text { peak }}$, the $\mathrm{VO}_{2 \max }$ and the VSAQ (Table III).

\section{Discussion}

The purpose of this study was to demonstrate the measurement properties of the Behavior section of the Psychosocial Determinants of Physical Activity among Coronary Heart Disease Patients Questionnaire, named the Physical Activity Behavior Questionnaire (QCAF) regarding the aspects of convergent and divergent validity, in a diverse population comprising both healthy and non-healthy individuals.

In the present study, the QCAF has presented acceptable levels of convergent validity hence were observed significant moderate positive adjusted correlations with the PA measure given by the total score of the Baecke-HPA questionnaire and the sub scores of Physical Exercise in Leisure and Locomotion and Leisure Activities. Larger correlations $(0.46 \mathrm{x}$ 0.16) were observed between the QCAF and the PEL domain score of the HPABaecke, which we attribute to the similarity of the question n.9 ("Do you play sport? If yes: which sport do you play more frequently? How many hours a week? How many months a year?"); than between the QCAF and the ALL domain score, that presents two alike questions to QCAF - n.14 ("During leisure time I walk") and n.16 ("How many minutes do you walk and/or cycle per day to and from work, school and shopping?").

The convergent validity was also confirmed by the analysis between the QCAF and the cardiorespiratory fitness measures; since significant small positive adjusted correlations with both direct $\left(\mathrm{VO}_{2 \text { peak }}\right.$ and $\left.\mathrm{VO}_{2 \max }\right)$ and indirect measures (VSAQ) were observed. 
The divergent validity was also established, once there was no significant correlation observed between the QCAF score and the Occupational PA sub score of the Baecke-HPA, as expected. This finding, in conjunction with the significant moderate correlation observed between the QCAF scores and the specific domain for leisure exercise of the Baecke, reinforces the capacity of the questionnaire of correctly measuring the specific domain of LTPA.

A relevant systematic review that assessed reliability of PA questionnaires as well as their validity evaluated against objective criterion methods, for use in all age groups, published between 1997 and 2011, suggests that assessing PA by means of objective monitoring has become widespread also when examining population levels of activity and imply that PA questionnaires remain as an active area of research and are now generally considered complementary to any objective measure (Helmerhorst, Brage, Warren, Besson \& Ekelund, 2012).

Corroborating with these findings, others (Helmerhorst, Brage,Warren, Besson \& Ekelund, 2012) support that the validity correlation coefficients from the greater part of current and recently developed PA questionnaires were considered low to moderate and were usually considered acceptable when presented as Pearson or Spearman correlation coefficients. These findings suggest that most PA questionnaires may be valid for ranking individuals' behavior, but their absolute validity is limited to quantify PA.

It is worthwhile to highlight that in Brazil there is no other validated questionnaire aimed at measuring walking exclusively, that is so simple and brief to be applied. Yet, the power of the QCAF must be reinforced - even being composed of a single item, this theory-based questionnaire was able to present significant correlations with the oxygen 
consumption, which is considered the gold standard measure for cardiorespiratory fitness; and frequently for PA, since there is no such a pattern for its assessment. These findings suggest that QCAF is precise and valid and point to satisfactory levels of confidence and validity.

An extensive review that assessed different validated methods for measuring PA states that simple and less intrusive tools, like questionnaires, will always be of relevance. Despite objective tools should be the measurement of choice to assess PA level, self-reported questionnaires remain valid and have many advantages (Ara, Aparicio-Ugarriza, Morales-Barco, de Souza, Mata \& González-Gross, 2015).

For decades, studies have provided strong and convincing evidence that PA can protect health. Knowledge is now consolidated concerning the significance of PA in relation to conditions as insulin resistance, type 2 diabetes, dyslipidemia, hypertension, obesity; heart and pulmonary diseases; muscle, bone and joint diseases and cancer, depression, asthma and type 1 diabetes (Ara, AparicioUgarriza, Morales-Barco, de Souza, Mata \& González-Gross, 2015). As a major result, new scientific questions (such as dose-response relationships and effectiveness of interventions aimed at increasing PA behaviors) are currently being studied. Despite this new kind of research requires more precision and accuracy in measurement than can be provided by the traditional survey methods, there will always be specific situations both in research and in clinical settings that will need self-reports.

It is also relevant to comprehend the relationship between urban design and physical activity is now a high priority for the prevention of chronic disease, since $t$ is estimated that by $2050,70 \%$ of the forecasted world population of 9.1 billion will live in urban areas (Christian, Bull, Middleton, Knuiman, Divitini, Hooper, Amarasinghe \& Giles-Corti, 2011). 
Therefore, walking will be a good option for a land PA.

In this sense, the QCAF brings an advent as it can be used not only in research scenarios, but also in clinical setting, since it can be rapidly and easily applied by any kind of health professional during a consultation, for example. Moreover, our study demonstrates that it can be used not only for patients with chronic health conditions, but also among those in a good health condition.

\subsection{Limitations and strengths}

The use of VSAQ and BaeckeHPA as interviews and not by selfadministering may be considered a methodological bias, despite it has happen elsewhere without harm to the questionnaire performance (Domingues, Gallani, Gobatto, Miura, Rodrigues \& Myers, 2011); Rodrigues, Gallani, Cornélio, Alexandre \& São-João, 2013).

The QCAF is a new questionnaire and this is the first study, to our knowledge, that aims to test its validity properties. Therefore, it is not possible to compare our results with others. Nevertheless, the findings described here are noticeable - the QCAF is a brief and simple questionnaire aimed at measuring the behavior of walking, which is considered a mild PA - and still, significant correlations were found with the two domains of the Baecke-HPA related to both physical exercise and locomotion activities. Even better, significant correlations were found with the cardiorespiratory fitness measures, including the direct measures of oxygen uptake, which are considered the gold standard for measuring cardiorespiratory fitness.

The QCAF provides to scientific community a valid and reliable tool to measure walking among healthy and non healthy individuals and nurses in this context can use it as a tool to identify walking levels of patients and develop, 
implement and evaluate interventions aimed at increasing PA levels.

\section{Conclusion}

The QCAF demonstrated evidences of convergent and divergent validity with indirect measures of physical activity and direct and indirect measures of cardiorespiratory fitness, suggesting that this questionnaire is a valid tool to estimate walking levels among a healthy or non-healthy population.

It is expected that the results of this study contribute to providing robust measure for evaluating PA for application in clinical nursing practice, for evaluation of nursing interventions aimed at promoting an active lifestyle among coronary artery disease and hypertension outpatients, as well as for maintenance of PA among healthy individuals. Future studies should consider including objective measures of PA in addition to self-report or consider recommendations to reduce self-report error.

\section{Acknowledgements}

The authors thank the São Paulo Foundation (FAPESP - Process 2010/ 10006-8) and the National Counsel of Technological and Scientific Development $(\mathrm{CNPq}$ - Process 150158/2013-0) for the research grants conceived.

\section{References}

Ajzen, I. (1988) Attitude, personality and behaviour. Milton Keynes: Open University Press.

Balady, G.J., Arena, R., Sietsema, K., Myers, J., Coke, L., Fletcher, G.F., Forman, D., Franklin, B., Guazzi, M., Gulati, M., Keteyian, S.J., Lavie, C.J., Macko, R., Mancini, D., Milani, R.V.; American Heart Association Exercise, Cardiac Rehabilitation, and Prevention Committee of the Council on Clinical Cardiology; Council on Epidemiology and Prevention; Council on Peripheral Vascular Disease; Interdisciplinary Council on Quality of Care and Outcomes Research. (2010). Clinician's Guide to cardiopulmonary exercise testing in adults: a scientific statement from the American Heart Association. Circulation, 122(2): 191-225.

Bassett Jr, D.R., Howley, E.T. (2000). Limiting factors for maximum oxygen uptake and determinants of endurance performance. Medicine 
and Science in Sports and Exercise, 32(1):70-84.

Brazilian Cardiology Society. (2010). VI Brazilian Guidelines on Hypertension. Arquivos Brasileiros de Cardiologia, 95(1, Suppl. 1), IIII. https://dx.doi.org/10.1590/S00 66-782X2010001700001

Christian HE, Bull FC, Middleton NJ, Knuiman MW, Divitini ML, Hooper P, Amarasinghe A, GilesCorti B. How important is the land use mix measure in understanding walking behaviour? Results from the RESIDE study. Int J Behav Nutr Phys Act. 2011 Jun 2;8:55. doi: 10.1186/1479-5868-8-55.

Cohen J. (1992). A power primer. Psychological Bulletin, 112(1): 155-159.

Cornélio, M.E., Gallani, M.C., Godin, G., Rodrigues, R.C., Mendez, R.D., Nadruz Junior, W. (2009). Development and reliability of an instrument to measure psychosocial determinants of salt consumption among hypertensive patients. Revista Latino-Americana de Enfermagem, 7(5):701-707.

Domingues, G.B.L., Gallani, M.C.B.J., Gobatto, C.A., Miura, C.T.P., Rodrigues, R.C.M., Myers, J. (2011). Cultural adaptation of an instrument to assess physical fitness in cardiac patients. Journal of Public Health, 45:276-285.

Farinatti, P.T.V. (2003). Presentation of a Portuguese version of the Compendium of Physical Activities: a contribution to researchers and professionals in exercise physiology. Brazilian Journal of Exercise Physiology, 2(2): 177-208.

Florindo, A.A., Latorre, M.R.D.O. (2003). Validation and reliability of the Baecke questionnaire for the evaluation of habitual physical activity in adult men. Brazilian Journal of Sports Medicine, 9:129135.

Florindo, A.A., Latorre, M.R.D.O., Jaime, P.C., Tanaka, T., Zerbini, C.A.F. (2004). Methodology to evaluation the habitual physical activity in men aged 50 years or more. Journal of Public Health, 38:307314.

Godin, G., Bélanger-Gravel, A., Amireault ,S., Vohl, M.C., Pérusse, L. (2011). The effect of mere-measurement of cognitions on physical activity behavior: a randomized controlled trial among overweight and obese individuals. International Journal of Behavioral Nutrition and Physical Activity, 11;8:2.

Ham, S.A., Kruger, J., Tudor-Locke, C. (2009). Participation by US adults in sports, exercise, and recreational physical activities. Journal of Physical Activity and Health, 6(1):6-14.

Helmerhorst, H.J.F., Brage, S.,Warren, J., Besson, H. \& Ekelund, U. (2012). A systematic review of reliability and objective criterion-related validity of physical activity questionnaires. International 
Journal of Behavioral Nutrition and Physical Activity, 9:103.

Lee, I.M., Rexrode, K.M., Cook, N.R., Manson, J.E., Buring, J.E. (2001). Physical Activity and Coronary Heart Disease in Women: Is "No Pain, No Gain" Passé?. Journal of the American Medical Association, 285(11):1447-54.

Meadows, K., Bentzen, N. \& Touw-Otten, F. (1996). Cross-cultural issues: an outline of the important principles in establishing cross-cultural validity in health outcome assessment. In: Hutchinson, A., Bentzen, N. \& König-Zahn, C. Cross Cultural Health Outcome Assessment; a user's guide [pp.3440]. The Netherlands: ERGHO European Research Group on Health Outcomes.

Mendez, R.D.R., Rodrigues, R.C.M., Cornélio, M.E., Gallani, M.C.B.J., Godin, G. (2010). Development of an instrument to measure psychosocial determinants of physical activity behavior among coronary heart disease patients. Revista da Escola de Enfermagem da USP, 44(3):583-94.

Meneghelo, R.S., Araújo, C.G.S., Stein, R., Mastrocolla, L.E., Albuquerque, P.F., \& Serra, S.M. (2010). III Diretrizes da Sociedade Brasileira de Cardiologia sobre teste ergométrico. Arquivos Brasileiros de Cardiologia, 95(5, Suppl. 1), 1-26. https://dx.doi.org/ 10.1590/S0066782X201000080000 1
Murtagh, E., Murphy, M., \& BooneHeinonen, J. (2010). Walking: the first steps in cardiovascular disease prevention. Current Opinion in Cardiology, 25(5), 490-496.

Myers, J., Buchanan, N., Smith, D., Neute,1 J., Bowes, E., Walsh, D., Froelicher, V.F. (1992). Individualized ramp treadmill. Observations on a new protocol. Chest, 101:236S-41S.

Myers, J., Do, D., Herbert, W., Ribisl, P., Froelicher, V.F. (1994). A nomogram to predict exercise capacity from a specific activity questionnaire and clinical data. American Journal of Cardiology, 73(8):591-6.

Nogueira, L.A.C., Baitelli, C., Alvarenga, R.M.P., Thuler, LC..S. (2012). Tradução e adaptação transcultural da Multiple Sclerosis Walking Scale - 12 (MSWS-12) para a língua portuguesa do Brasil. Public Health Reports, 28(5):998-1004.

Ono, R., Hirata, S., Yamada, M., Nishiyama, T., Kurosaka, M., Tamura, Y. (2007). Reliability and validity of the Baecke physical activity questionnaire in adult women with hip disorders. BMC Musculoskeletal Disorders, 8,61.

Pereira, M.A., Folsom, A.R., McGovern, P.G., Carpenter, M., Arnett, D.K., Liao, D., Szklo, M. \& Hutchinson, R.G. (1999). Physical activity and incident hypertension in black and white adults: the atherosclerosis risk in communities study. 
Preventive Medicine, 1999, 28:304-312.

Rodrigues, R.C.M., Gallani, M.C.B.J., Cornélio, M.E., Alexandre, N.M.C., São-João, T.M. (2013). The 'Moving Heart Program': an intervention to improve physical activity among patients with coronary heart disease. Revista Latino-Americana de Enfermagem, 21(Spec):180-189.

Spana, T.M., Rodrigues, R.C., Gallani, M.C., Mendez, R.D. (2010). Physical activity behavior among coronary outpatients according to socio-demographic and clinical profile. Brazilian Journal of Nursing, 63(5):741-748.

West, M.A., Parry, M., Asher, R., Key, A., Walker, P., Loughney, L., Pintus, S., Duffy, N., Jack, S., Torella, F. (2015). The Effect of betablockade on objectively measured physical fitness in patients with abdominal aortic aneurysms--A blinded interventional study. British Journal of Anaesthesia, 114(6):878-885. 